\title{
Preparation of a mesoporous sorption complex catalyst and its evaluation in reactive sorption enhanced reforming ${ }^{*}$
}

\author{
Fan ZHANG ${ }^{1,2}$, Qi TANG ${ }^{1,2}$, Su-fang WU $\mathrm{W}^{\dagger 1,2}$ \\ $\left({ }^{1}\right.$ Key Laboratory of Biomass Chemical Engineering of Ministry of Education, Zhejiang University, Hangzhou 310027, China) \\ $\left({ }^{2}\right.$ Department of Chemical and Biological Engineering, Zhejiang University, Hangzhou 310027, China) \\ †E-mail: wsf@zju.edu.cn
}

Received June 3, 2013; Revision accepted Oct. 23, 2013; Crosschecked Nov. 8, 2013

\begin{abstract}
A mesoporous sorption complex catalyst was prepared by pore-forming modification and evaluated by the $\mathrm{CO}_{2}$ reactive sorption enhanced reforming (ReSER) process, which is used to produce hydrogen from methane. Three samples of polyethylene glycol (PEG) with molecular weights between 2000 and 20000 were added as templates into a mixed slurry to create catalysts with different pore properties by further formation and calcination. The pore characteristics determined by BrunauerEmmett-Teller (BET) analysis showed that one of the mesoporous catalysts, named M-NiAlCa-6000, had a pore size of $9.2 \mathrm{~nm}$ and a surface area of $70.52 \mathrm{~m}^{2} / \mathrm{g}$ and the $\mathrm{CO}_{2}$ sorption capacity of this catalyst was $44 \%$ higher than that of the catalyst without the PEG 6000 modification. The catalyst was evaluated in the ReSER process in a fixed-bed reactor system at $0.1 \mathrm{MPa}$ and $600{ }^{\circ} \mathrm{C}$ with an $\mathrm{H}_{2} \mathrm{O} / \mathrm{CH}_{4}$ molar ratio of 4 . An $\mathrm{H}_{2}$ concentration of $94.2 \%$ and a $\mathrm{CH}_{4}$ conversion of $86.0 \%$ were obtained at a carbon space velocity of $1700 \mathrm{~h}^{-1}$, while $\mathrm{CO}_{2}$ was hardly detected.
\end{abstract}

Key words: Hydrogen, $\mathrm{Ni}$ catalyst, Mesoporous, Steam methane reforming, $\mathrm{CO}_{2}$ sorption doi: 10.1631 jzus.A1300193

Document code: A

CLC number: TQ110.3

\section{Introduction}

The process of adding $\mathrm{CO}_{2}$ sorbent during steam methane reforming (SMR) is a potential way of reducing emission of the greenhouse gas $\mathrm{CO}_{2}$ and enhancing the reforming process for hydrogen production (Han and Harrison, 1994; Carvill et al., 1996; Balasubramanian et al., 1999; Ding and Alpay, 2000; Xiu et al., 2003; Harrison, 2008; Chanburanasiri et al., 2011; Wang et al., 2011). He and Wu (2007) developed a ReSER process that uses nano- $\mathrm{CaO}$ as the $\mathrm{CO}_{2}$ reactive adsorbent in a sorption complex catalyst to produce high-purity hydrogen with control of $\mathrm{CO}_{2}$ emissions. The sorption complex catalyst contains nano- $\mathrm{CaO}$ as the $\mathrm{CO}_{2}$ reactive adsorbent and $\mathrm{NiO}$ as

\footnotetext{
${ }^{\ddagger}$ Corresponding author

* Project (No. 20876142) supported by the National Natural Science Foundation of China

C Zhejiang University and Springer-Verlag Berlin Heidelberg 2013
}

the reforming catalyst in one microsphere particle. The exothermic reaction of $\mathrm{CaO}$ with $\mathrm{CO}_{2}$ enhances the endothermic reaction of steam reforming in each particle (Wu et al., 2008; 2010).

As a new catalyst, the sorption complex catalyst can be further improved in activity and stability. Wu and Wang (2010) and Feng et al. (2012) focused on a method of adding assistant catalysts such as $\mathrm{ZrO}_{2}$ or $\mathrm{La}_{2} \mathrm{O}_{3}$. Although both studies reported some degree of improvement in stability, the catalysts were all evaluated at a very low carbon space velocity of $340 \mathrm{~h}^{-1}$, which is far from the industrial requirement of at least $1000 \mathrm{~h}^{-1}$. Based on the features of the sorption complex catalyst, the reaction between $\mathrm{CaO}$ and $\mathrm{CO}_{2}$ is the most important reaction. Additionally, the available pore structure will affect the gas-solid reactivity of $\mathrm{CaO}$ with $\mathrm{CO}_{2}$, thus affecting the SMR reaction in terms of both heat and mass transmission.

Previous studies (Inoue et al., 1988; 1991; Oyekunle and Ikpekri, 2004; Gong et al., 2005) have 
shown that a larger pore size and a greater number of pores promote the reactions by facilitating the transmission of heat and mass into and out of the catalyst. Moreover, it is well known that high porosity implies high surface area, which provides a large number of reactive sites. Seo et al. (2009) increased the pore size of a Ni-based catalyst from $4.2 \mathrm{~nm}$ to $9.6 \mathrm{~nm}$, and obtained an $8 \%-15 \%$ increase in the $\mathrm{CH}_{4}$ conversion rate. Sun et al. (2010) studied the pore structure of a $\mathrm{Ni}$ catalyst for the $\mathrm{CO}_{2}$ reforming of $\mathrm{CH}_{4}$ and found that catalysts with large pore volumes showed very high catalytic activity. The catalyst developed in previous study (Wu and Wang, 2010; Feng et al., 2012) for the ReSER process exhibits a pore size smaller than $5 \mathrm{~nm}$ and pore volume less than $0.2 \mathrm{~cm}^{3} / \mathrm{g}$. Therefore, it is necessary and interesting to study the effect of pore expansion on the catalytic performance of the sorption complex in the ReSER process.

The methods (Inoue et al., 1994; Liu et al., 2009) used to improve catalyst porosity use polyethylene glycol (PEG), a polymer that exhibits good dispersion and solubility, as a template. When PEG is mixed with a catalyst or catalyst support, it decomposes at $200-400{ }^{\circ} \mathrm{C}$ and creates many pores of different sizes, depending on its degree of polymerization.

In this study, we used PEG as a template to prepare a mesoporous sorption complex catalyst. The catalyst was then evaluated with respect to its $\mathrm{CO}_{2}$ sorption properties and hydrogen production performance in the ReSER process.

\section{Experimental}

\subsection{Preparation of mesoporous sorption complex catalyst}

Nano- $\mathrm{CaCO}_{3}$ (Huzhou Linghua Co., Ltd., China) was used as a nano-CaO-based adsorbent precursor, and $\mathrm{Ni}\left(\mathrm{NO}_{3}\right)_{2} \cdot 6 \mathrm{H}_{2} \mathrm{O}$ (98\% purity, Shanghai Hengxin Chemical Reagent Co., Ltd., China) was used as the $\mathrm{Ni}$ source. PEG (analytical reagent, Sinopharm Chemical Reagent Co., Ltd., China) with molecular weights of 2000,6000 , and 20000 were chosen as templates to obtain the desired mesoporous structures. The sorption complex catalyst was prepared by the slurry mixing method. PEG was dissolved in hot water before being added to a nano- $\mathrm{CaCO}_{3}$ water-suspended solution, and stirred to make a slurry. Then, an alumina sol (10\%, Zibo Longao Co., Ltd., China) and a $\mathrm{Ni}\left(\mathrm{NO}_{3}\right)_{2} \cdot 6 \mathrm{H}_{2} \mathrm{O}$ solution were added to the slurry. The slurry was then dried, extruded, and calcined at $500-800{ }^{\circ} \mathrm{C}$ in a muffle furnace. The catalysts with and without added PEG were denoted as M-NiAlCa- $n$ (with added PEG, where $n$ represents the molecular weight of the PEG that was used) and N-NiAlCa (without added PEG).

\subsection{Characterization of mesoporous sorption complex catalyst}

The surface area and pore structures of the catalysts were determined by the Brunauer-EmmettTeller (BET) method (nitrogen physisorption) using a MiCromeritiCs BELSoRP-mini II device (BEL Japan, Inc.). The crystalline phase of the catalyst was determined by X-ray diffraction (XRD, D/MAX-RAX, Rigaku, Japan). A temperature-programmed reduction (TPR) was carried out to test the interaction between $\mathrm{NiO}$ and the support of the catalysts (TP-5000III, Tianjin Xianquan Industry and Trade Development Co., Ltd.); tubes were filled with $50 \mathrm{mg}$ of catalyst, placed under a feed gas of $5 \% \mathrm{H}_{2}$ in $\mathrm{N}_{2}$ and heated from $373 \mathrm{~K}$ to $1073 \mathrm{~K}$ at $10 \mathrm{~K} / \mathrm{min}$.

\subsection{Adsorption properties of mesoporous sorption complex catalysts}

Thermal gravimetric analysis (TGA) (type Pyris 1, Perkin Elmer Corporation, America) was used to measure the adsorption properties of mesoporous sorption complex catalysts. First, 1-2 mg of the catalysts was placed on the testing platform. The adsorption stage temperature was set to $600{ }^{\circ} \mathrm{C}$ and held for $10 \mathrm{~min}$ in $20 \% \mathrm{CO}_{2} / 80 \% \mathrm{~N}_{2}$, and the desorption stage temperature was set to $750{ }^{\circ} \mathrm{C}$ and held for 10 min in $\mathrm{N}_{2}$ atmosphere. Before the adsorptiondecomposition program, $\mathrm{CaCO}_{3}$ in the catalyst was first decomposed to $\mathrm{CaO}$ at $750{ }^{\circ} \mathrm{C}$ in TGA. The adsorption capacity $(\mathrm{mol} / \mathrm{kg})$ was defined as the molar mass of the actual adsorption of $\mathrm{CO}_{2}$ per mass of catalyst. The reason why we chose a reaction temperature of $600{ }^{\circ} \mathrm{C}$ and the regeneration temperature of $800{ }^{\circ} \mathrm{C}$ is that, in our previous studies, $\mathrm{He}$ and $\mathrm{Wu}$ (2007) determined that $600-640{ }^{\circ} \mathrm{C}$ is the optimal temperature for the ReSER process. In this research, 
we chose $600{ }^{\circ} \mathrm{C}$ as our reaction temperature. Also, the decomposition temperature of a sorption complex catalyst completely is $750{ }^{\circ} \mathrm{C}$ by TGA testing. Considering the effect of mass and heat transfer, we chose the regeneration temperature as $800{ }^{\circ} \mathrm{C}$ to decompose the nano- $\mathrm{CaCO}_{3}$ in the catalyst completely in a fixed-bed.

\subsection{Evaluation method of ReSER hydrogen production}

Fig. 1 shows the laboratory-scale fixed-bed reactor that was used to evaluate the activity of the mesoporous sorption complex catalysts during the ReSER process. The catalyst powder was placed in the flat-temperature zone in the fixed-bed reactor. The temperature of the reactor was controlled by a temperature-control device. $\mathrm{CH}_{4}, \mathrm{H}_{2}$, and $\mathrm{N}_{2}$ were supplied from steel cylinders, and three mass flow controllers were used in front of the reactor to control their flow rates. Steam came from water vaporization and the flow of water was controlled by a highprecision water pump. The product gas after reaction was piped in gas chromatography (GC) to be analyzed, and the test results are the percentage concentrations of $\mathrm{CH}_{4}, \mathrm{CO}_{2}$, and $\mathrm{CO}$. The reaction conditions were: a temperature of $600{ }^{\circ} \mathrm{C}$, a pressure of $0.1 \mathrm{MPa}$, and an $\mathrm{H}_{2} \mathrm{O} / \mathrm{CH}_{4}$ molar ratio of 4 . Before the reaction, the catalyst was first regenerated to decompose $\mathrm{CaCO}_{3}$ to form $\mathrm{CaO}$ at the regeneration temperature of $800{ }^{\circ} \mathrm{C}$ in a $\mathrm{N}_{2}$ atmosphere. Then $\mathrm{NiO}$ was reduced to form $\mathrm{Ni}$ by diluting $\mathrm{H}_{2}$ with $\mathrm{N}_{2}$.

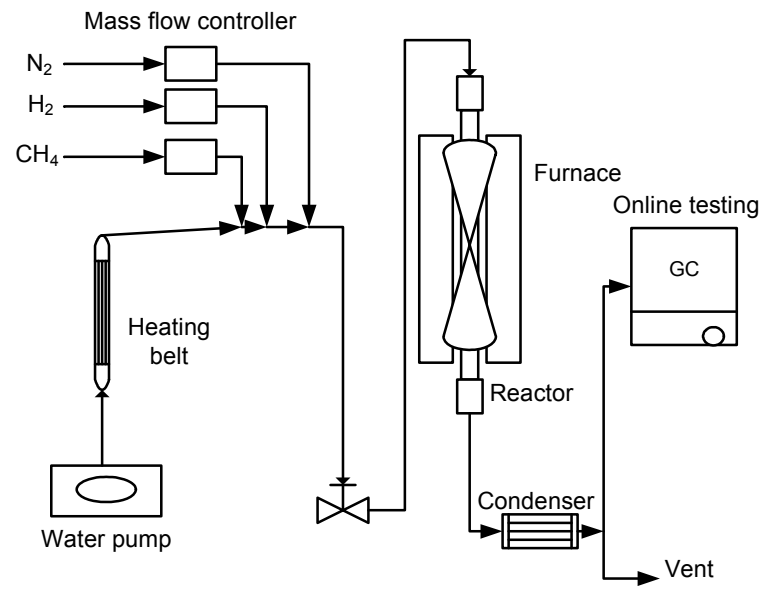

Fig. 1 Reaction system of the ReSER process for hydrogen production

\section{Results and discussion}

\subsection{Pore properties with PEG modification}

The pore properties and surface areas of the catalysts modified with PEG with different molecular weights were tested by the BET method. Fig. 2 shows
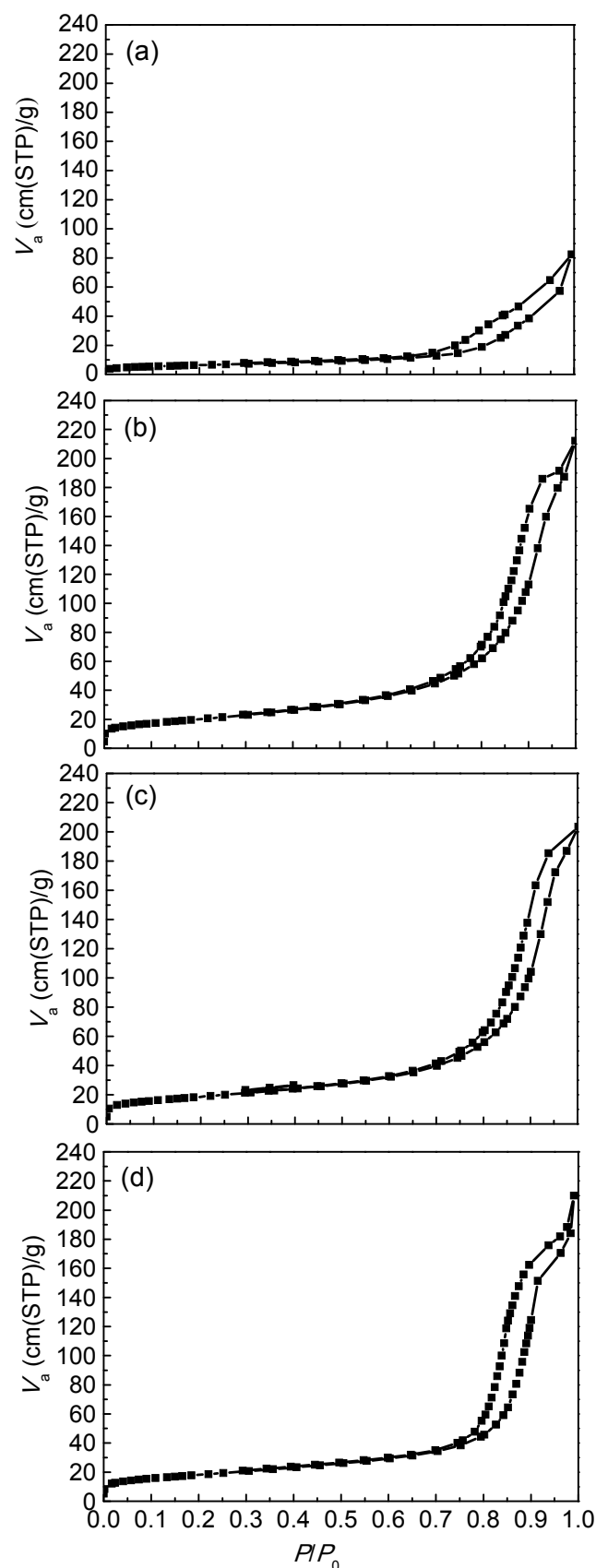

Fig. $2 \mathrm{~N}_{2}$ adsorption/desorption curves of different catalysts

(a) N-NiAlCa; (b) M-NiAlCa-2000; (c) M-NiAlCa-6000;

(d) M-NiAlCa-20000. $V_{\text {a }}$ presents the adsorption volume per gram adsorbent, and $P / P_{0}$ presents the partial pressure 
the $\mathrm{N}_{2}$ adsorption/desorption curves of the catalysts. A typical type-IV hysteresis loop is observed in Figs. $2 \mathrm{~b}-2 \mathrm{~d}$, indicating that by using PEG as the template, a mesoporous framework is formed and stabilized in the reflux stage. However, N-NiAlCa, prepared by the same procedure without the addition of PEG, does not show a distinct mesoporous framework, as shown in Fig. 2a.

Fig. 3 shows the pore size $\left(r_{\mathrm{p}}\right)$ distribution curves of the catalysts. M-NiAlCa-2000, M-NiAlCa-6000, and M-NiAlCa-20000 show increasing peak values ranging from $7.0 \mathrm{~nm}$ to $10.8 \mathrm{~nm}$.

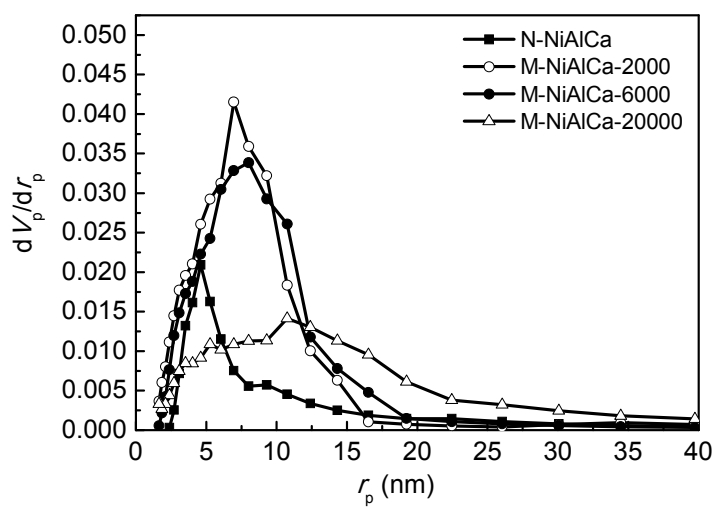

Fig. 3 Pore size distribution curves of the catalysts

Table 1 shows the surface area, pore size, and pore volume of sorption complex catalysts. As the molecular weight of the added PEG increases from 2000 to 20000 , the average pore size increases from $8.0 \mathrm{~nm}$ to $11.8 \mathrm{~nm}$. The surface area and pore volume of the sorption complex catalysts increase by $2-3$ times with added PEG. However, with the increase in molecular weight of PEG, the surface area decreases gradually. This is because, for the same mass of added PEG, the higher-molecular-weight sample contains fewer but larger molecules and thus produces fewer pores and a smaller surface area but a larger pore size. Combining the results shown in Table 1 and

Table 1 Pore properties of sorption complex catalysts

\begin{tabular}{cccc}
\hline Sample & $\begin{array}{c}\text { Average } \\
\text { pore size } \\
(\mathrm{nm})\end{array}$ & $\begin{array}{c}\text { Surface } \\
\text { area } \\
\left(\mathrm{m}^{2} / \mathrm{g}\right)\end{array}$ & $\begin{array}{c}\text { Pore } \\
\text { volume } \\
\left(\mathrm{cm}^{3} / \mathrm{g}\right)\end{array}$ \\
\hline N-NiAlCa & 7.2 & 22.56 & 0.13 \\
M-NiAlCa-2000 & 8.0 & 67.52 & 0.30 \\
M-NiAlCa-6000 & 9.2 & 65.79 & 0.31 \\
M-NiAlCa-20000 & 11.8 & 46.98 & 0.28 \\
\hline
\end{tabular}

Figs. 2 and 3, we conclude that the catalysts modified with PEG2000 and PEG6000 show good average pore sizes and surface areas. The pore analysis above indicates successful pore formation.

\subsection{Adsorption properties by PEG modification}

The sorption complex catalyst is a combination of a $\mathrm{CO}_{2}$ adsorbent and a reforming catalyst. The sorption properties constitute one of the key factors that affect the kinetics of the reforming reaction. The sorption properties of the catalysts $\mathrm{N}-\mathrm{NiAlCa}$, M-NiAlCa-2000, and M-NiAlCa-6000 were tested by TGA, and the results are shown in Figs. 4-6.

Fig. 4 shows that M-NiAlCa-6000 has the largest sorption capacity. Fig. 5 shows the sorption rate calculated from the data of Fig. 4 by a differential method, and it is clear that the sorption rate of M-NiAlCa-6000 is the highest. Based on ion migration mechanism, $\mathrm{CO}_{2}$ molecules are adsorbed on the catalyst surface and react with $\mathrm{O}^{2-}$ ions to form $\mathrm{CO}_{3}{ }^{2-}$ ions. At the beginning of the adsorption reaction, the number of $\mathrm{CO}_{3}{ }^{2-}$ ions in the reaction system is few, and thus the initial reaction rate is slow. As the reaction progresses, the number of $\mathrm{CO}_{3}{ }^{2-}$ ions in the reaction system increases, and thus the reaction rate increases. That stage is the so-called fast adsorption stage, when $\mathrm{CO}_{2}$ molecules react with external $\mathrm{CaO}$, and the process is reaction-controlled. After that, the reaction moves to a slow-adsorption stage, because the $\mathrm{CO}_{2}$ molecules must penetrate the product $\mathrm{CaCO}_{3}$ layer to react with the internal $\mathrm{CaO}$, so the reaction rate is slower, and the process is diffusion-controlled.

Fig. 6 illustrates the durability of the sorption capacity of the catalysts. It is clear that M-NiAlCa6000 exhibits the best durability and is more stable than M-NiAlCa-2000.

The above results show that the sorption complex catalyst M-NiAlCa-6000 with a larger pore size of $9.2 \mathrm{~nm}$ and a higher surface area of $65.79 \mathrm{~m}^{2} / \mathrm{g}$ yields a better sorption capacity and sorption rate.

The experimental results discussed above suggest that, first, a larger surface area provides more reactive $\mathrm{CaO}$ sites for $\mathrm{CO}_{2}$ adsorption reaction, thus increasing the sorption capacity and sorption rate. This has also been shown in (Wu and Wang, 2010), in which a catalyst with a surface area of $69.5 \mathrm{~m}^{2} / \mathrm{g}$ has a higher sorption capacity than a catalyst with a surface 


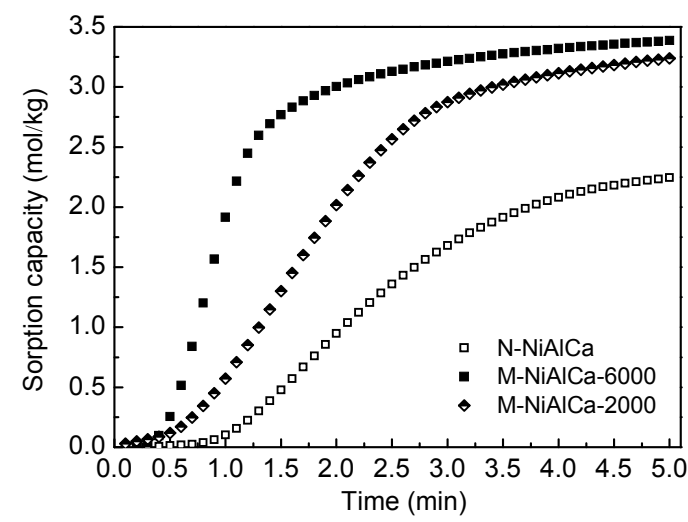

Fig. 4 Sorption capacity of the catalysts

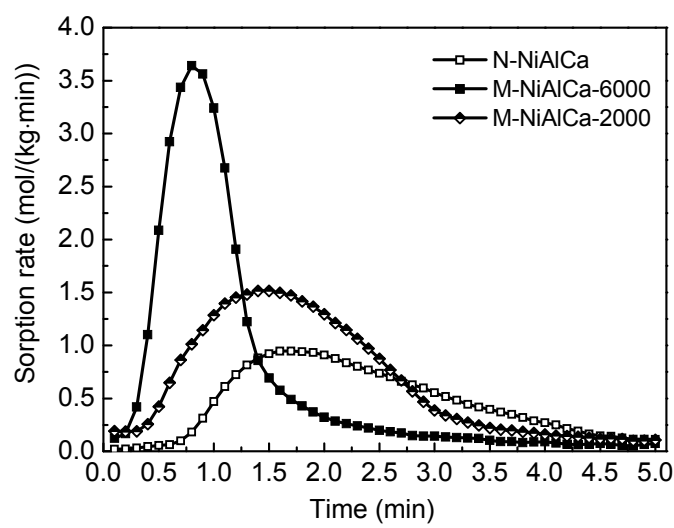

Fig. 5 Sorption rate of the catalysts

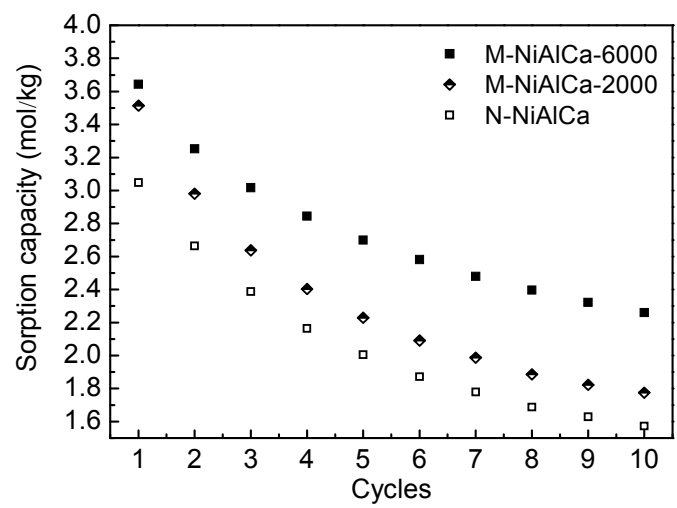

Fig. 6 Durability of the catalysts' sorption capacity area of $30.8 \mathrm{~m}^{2} / \mathrm{g}$; second, the larger pore size facilitates the transmission of heat and mass, enhancing the reaction of $\mathrm{CO}_{2}$ with $\mathrm{CaO}$ and increasing the sorption capacity and reaction rate. Therefore, by carefully considering the BET and TGA results, we chose the mesoporous catalyst M-NiAlCa-6000 as the subject of our study on hydrogen production in the ReSER process. The catalyst N-NiAlCa was also evaluated in the ReSER process for comparison.

\subsection{Performance of hydrogen production in Re- SER process}

The performances of the sorption complex catalysts N-NiAlCa and M-NiAlCa-6000 with respect to the ReSER hydrogen production process were evaluated on a laboratory-scale fixed-bed reactor. The highest $\mathrm{H}_{2}$ concentration and $\mathrm{CH}_{4}$ conversion rate in the sorption-enhanced segment were obtained under different carbon space velocities (Table 2). Both catalysts yielded similar $\mathrm{H}_{2}$ concentrations above $95 \%$ and $\mathrm{CH}_{4}$ conversion rates of approximately $90 \%$ in the sorption-enhanced segment when the carbon space velocity was only $340 \mathrm{~h}^{-1}$. However, when the carbon space velocity increased to $1020 \mathrm{~h}^{-1}$, the catalyst $\mathrm{N}-\mathrm{NiAlCa}$ produced a lower $\mathrm{H}_{2}$ concentration, $81.1 \%$, and exhibited a reduced $\mathrm{CH}_{4}$ conversion rate, $53.1 \%$. By comparison, for the mesoporous catalyst M-NiAlCa-6000, when the carbon space velocity increased to $1020 \mathrm{~h}^{-1}$, the $\mathrm{H}_{2}$ concentration and $\mathrm{CH}_{4}$ conversion rate were still $96.8 \%$ and $94 \%$, respectively. When the carbon space velocity increased to $1700 \mathrm{~h}^{-1}$, the $\mathrm{H}_{2}$ concentration and $\mathrm{CH}_{4}$ conversion were still $94.2 \%$ and $86 \%$, respectively. Both the $\mathrm{CH}_{4}$ conversion rate and $\mathrm{H}_{2}$ concentration of $\mathrm{M}$ NiAlCa-6000 were higher than those of N-NiAlCa with the increase of the carbon space velocity. The high concentration of hydrogen also indicated low $\mathrm{CO}_{2}$ emission.

Table 2 ReSER hydrogen production of N-NiAICa and M-NiAlCa-6000 catalysts

\begin{tabular}{|c|c|c|c|c|}
\hline \multirow{2}{*}{$\begin{array}{l}\text { Space velocity } \\
\qquad\left(\mathrm{h}^{-1}\right)\end{array}$} & \multicolumn{2}{|c|}{ M-NiAlCa-6000 } & \multicolumn{2}{|c|}{$\mathrm{N}-\mathrm{NiAlCa}$} \\
\hline & $\begin{array}{c}\mathrm{H}_{2} \text { concentration } \\
(\%)\end{array}$ & $\begin{array}{c}\mathrm{CH}_{4} \text { conversion } \\
(\%)\end{array}$ & $\begin{array}{c}\mathrm{H}_{2} \text { concentration } \\
(\%)\end{array}$ & $\begin{array}{c}\mathrm{CH}_{4} \text { conversion } \\
(\%)\end{array}$ \\
\hline 340 & 95.8 & 89.9 & 90.6 & 95.5 \\
\hline 680 & 95.3 & 85.1 & 84.4 & 94.5 \\
\hline 1020 & 96.8 & 94.0 & 53.1 & 81.1 \\
\hline 1360 & 95.0 & 95.6 & & \\
\hline 1700 & 94.2 & 86.0 & & \\
\hline
\end{tabular}


Table 3 shows the activity of catalysts reported by Feng et al. (2012). They modified a sorption complex catalyst with $\mathrm{La}_{2} \mathrm{O}_{3}$ (named LNCA); LNCA exhibited a surface area of $29.18 \mathrm{~m}^{2} / \mathrm{g}$ and pore size of $4.6 \mathrm{~nm}$. The performance of LNCA in the ReSER process was then evaluated in a fixed-bed reactor. Compared with Tables 2 and 3, it is clear that the catalyst M-NiAlCa-6000 can be used with a higher carbon space velocity. Moreover, M-NiAlCa-6000 yields a higher $\mathrm{CH}_{4}$ conversion and $\mathrm{H}_{2}$ concentration than LNCA.

Table 3 ReSER hydrogen production of catalyst modified by $\mathrm{La}_{2} \mathrm{O}_{3}$ reported in (Feng et al., 2012)

\begin{tabular}{ccc}
\hline $\begin{array}{c}\text { Space velocity } \\
\left(\mathrm{h}^{-1}\right)\end{array}$ & $\begin{array}{c}\mathrm{H}_{2} \text { concentration } \\
(\%)\end{array}$ & $\begin{array}{c}\mathrm{CH}_{4} \text { conversion } \\
(\%)\end{array}$ \\
\hline 396 & 93.1 & 89.4 \\
792 & 89.6 & 87.6 \\
1188 & 90.2 & 85.1 \\
1386 & 85.4 & 65.4 \\
\hline
\end{tabular}

These results indicate that mesoporous catalysts with a large surface area of $65.79 \mathrm{~m}^{2} / \mathrm{g}$ and pore size of $9.2 \mathrm{~nm}$ exhibit higher activity and would be more suitable for industrial application.

\subsection{Performance of the mesoporous catalyst}

The microscopic characteristics of a catalyst can provide an explanation for the catalyst's macroscopic performance. XRD was used to test the phase characteristics of the catalyst, including grain size and metal dispersion (Fig. 7).

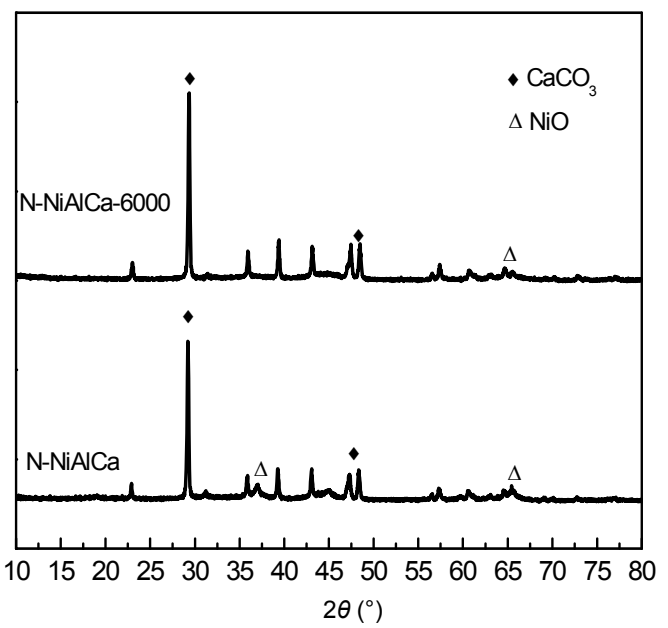

Fig. 7 XRD spectra of catalysts N-NiAICa and M-NiAICa-6000
The characteristic peaks of fresh, unreduced complex catalysts N-NiAlCa and M-NiAlCa-6000 mainly belong to $\mathrm{CaCO}_{3}$ and $\mathrm{NiO} . \mathrm{Al}_{2} \mathrm{O}_{3}$ peaks were not detected. No characteristic $\mathrm{NiO}$ peak was detected at $35^{\circ}-40^{\circ}$ for $\mathrm{M}-\mathrm{NiAlCa}-6000$, and the strength of the characteristic peak at $60^{\circ}-70^{\circ}$ is weaker compared with that observed for N-NiAlCa, which suggests that the dispersion of the active component $\mathrm{NiO}$ in M-NiAlCa-6000 is better than in N-NiAlCa. The NiO grain sizes calculated by the Scherrer formula were $20.38 \mathrm{~nm}$ and $11.57 \mathrm{~nm}$ for fresh N-NiAlCa and M-NiAlCa-6000, respectively. This means that the catalyst with the more porous structure has a smaller $\mathrm{NiO}$ grain size. The porous catalyst exhibited a larger surface area, leading to a better dispersion of the active component $\mathrm{NiO}$; and thus more reactive sites are created for the ReSER process, thus improving the activity of the catalyst.

A TPR test was conducted to study the effect of the strong metal-support interaction (SMSI effect) of the catalyst (Fig. 8). Xu et al. (2001) and Feng et al. (2009) showed that the interaction between the active component and the support in catalysis is one of the most important factors affecting catalyst performance. The weak interaction related to the low temperature peak $\left(<450{ }^{\circ} \mathrm{C}\right)$ in the TPR spectrum will result in the migration and clustering of the active $\mathrm{Ni}$, and thus will reduce the activity of the catalyst during the reaction; while the very strong interaction related to the high temperature peak $\left(>750^{\circ} \mathrm{C}\right)$ in the TPR spectrum will lead to the formation of spinel, which has no activity in the reforming reaction. Therefore, both weak and very strong metal-support interactions will lead to bad catalyst performance. The shared reduction peak of N-NiAlCa at $360^{\circ} \mathrm{C}$ is attributed to free $\mathrm{NiO}$, but the peak of M-NiAlCa-6000 at the same temperature is not as distinct. That means that $\mathrm{NiO}$ with weak interaction with the support in the catalyst M-NiAlCa-6000 is less than that in the catalyst N-NiAlCa. Dueso et al. (2010) believed that large grain sizes are easier to reduce for the same type of $\mathrm{NiO}$, which also implies that the $\mathrm{NiO}$ grain size in catalyst decreases after adding PEG. The peak at 500-700 ${ }^{\circ} \mathrm{C}$ represents fixed $\mathrm{NiO}$, which indicates a stronger interaction between the active components and the support. The integrated area between $500{ }^{\circ} \mathrm{C}$ and $700{ }^{\circ} \mathrm{C}$ for the catalyst M-NiAlCa-6000 is larger than that of N-NiAlCa, indicating that the catalyst 
M-NiAlCa-6000 has an appropriate metal-support interaction. The reduction peak of N-NiAlCa at approximately $880{ }^{\circ} \mathrm{C}$ represents nickel-aluminum spinel $\mathrm{NiAl}_{2} \mathrm{O}_{4}$ (Hao et al., 2009), and does not occur in M-NiAlCa-6000. The SMSI effect of a catalyst can be regulated to be more suitable by modification of the pore-forming characteristics.

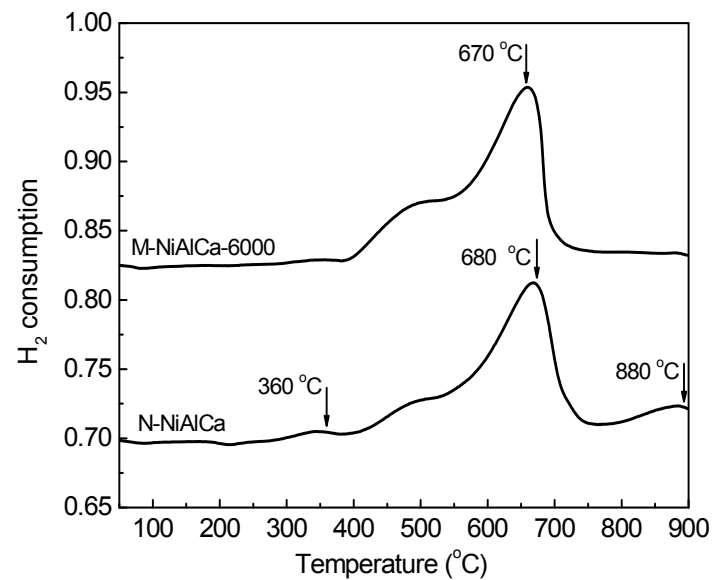

Fig. 8 TPR spectra comparison of catalysts N-NiAICa and M-NiAICa-6000

Consequently, the better performance of the catalyst M-NiAlCa-6000 may be attributed to the addition of PEG for pore formation. A mesoporous structure was obtained after PEG was added and then decomposed at the calcination temperature. Larger surface area and pore size were obtained in the mesoporous catalyst, which facilitate the transmission of mass and heat. Moreover, during modification, $\mathrm{NiO}$ disperses more evenly on the support surface and the $\mathrm{NiO}$ grain size decreases, as determined by XRD. Additionally, the TPR results show that the generation of $\mathrm{NiAl}_{2} \mathrm{O}_{4}$ is inhibited, while more active sites emerge on the support surface.

\section{Conclusions}

The mesoporous catalyst M-NiAlCa-6000, created using PEG 6000 as a template, showed the best pore properties of all the samples with a surface area of $65.79 \mathrm{~m}^{2} / \mathrm{g}$ and an average pore size of $9.2 \mathrm{~nm}$. The $\mathrm{CO}_{2}$ sorption capacity of the catalyst was $44 \%$ higher than that of the unmodified N-NiAlCa catalyst, and the $\mathrm{CO}_{2}$ sorption rate was accordingly faster. The mesoporous sorption complex catalyst produced an $\mathrm{H}_{2}$ concentration of $94.2 \%$ at a carbon space velocity of $1700 \mathrm{~h}^{-1}$ and exhibited a $\mathrm{CH}_{4}$ conversion rate of $86.0 \%$. XRD results demonstrated that the Ni grain size in the mesoporous catalysts was smaller, while TPR results demonstrated that there were more active sites in the mesoporous catalyst.

\section{References}

Balasubramanian, B., Lopez Ortiz, A., Kaytakoglu, S., Harrison, D.P., 1999. Hydrogen from methane in a single-step process. Chemical Engineering Science, 54(15-16):35433552. [doi:10.1016/S0009-2509(98)00425-4]

Carvill, B.T., Hufton, J.R., Anand, M., Sircar, S., 1996. Sorption-enhanced reaction process. AIChE Journal, 42(10):2765-2772. [doi:10.1002/aic.690421008]

Chanburanasiri, N., Ribeiro, A.M., Rodrigues, A.E., Arpornwichanop, A., Laosiripojana, N., Praserthdam, P., Assabumrungrat, S., 2011. Hydrogen production via sorption enhanced steam methane reforming process using $\mathrm{Ni} / \mathrm{CaO}$ multifunctional catalyst. Industrial \& Engineering Chemistry Research, 50(24):13662-13671. [doi:10. 1021/ie201226j]

Ding, Y., Alpay, E., 2000. Adsorption-enhanced steammethane reforming. Chemical Engineering Science, 55(18):3929-3940. [doi:10.1016/S0009-2509(99)00597-7]

Dueso, C., Abad, A., García-Labiano, F., de Diego, L.F., Gayán, P., Adánez, J., Lyngfelt, A., 2010. Reactivity of a $\mathrm{NiO} / \mathrm{Al}_{2} \mathrm{O}_{3}$ oxygen carrier prepared by impregnation for chemical-looping combustion. Fuel, 89(11):3399-3409. [doi:10.1016/j.fuel.2010.03.043]

Feng, H.Z., Lan, P.Q., Wu, S.F., 2012. A study on the stability of a $\mathrm{NiO}-\mathrm{CaO} / \mathrm{Al}_{2} \mathrm{O}_{3}$ complex catalyst by $\mathrm{La}_{2} \mathrm{O}_{3}$ modification for hydrogen production. International Journal of Hydrogen Energy, 37(19):14161-14166. [doi:10.1016/j. ijhydene.2012.06.099]

Feng, J.T., Lin, Y.J., Evans, D.G., Duan, X., Li, D.Q., 2009. Enhanced metal dispersion and hydrodechlorination properties of a $\mathrm{Ni} / \mathrm{Al}_{2} \mathrm{O}_{3}$ catalyst derived from layered double hydroxides. Journal of Catalysis, 266(2):351-358. [doi:10.1016/j.jcat.2009.07.001]

Gong, L.Q., Chen, J.X., Qiu, Y.J., Zhang, J.Y., 2005. Effects of calcinations temperature on structure and catalytic performance of $\mathrm{Ni} / \mathrm{MgO}-\mathrm{Al}_{2} \mathrm{O}_{3}$ catalysts for partial oxidation of methane. Journal of Fuel Chemistry and Technology, 33(2):224-228 (in Chinese).

Han, C., Harrison, D.P., 1994. Simultaneous shift reaction and carbon dioxide separation for the direct production of hydrogen. Chemical Engineering Science, 49(24):58755883. [doi:10.1016/0009-2509(94)00266-5]

Hao, Z.G., Zhu, Q.S., Jiang, Z., Hou, B.L., Li, H.Z., 2009. Characterization of aerogel $\mathrm{Ni} / \mathrm{Al}_{2} \mathrm{O}_{3}$ catalysts and investigation on their stability for $\mathrm{CH}_{4}-\mathrm{CO}_{2}$ reforming in a fluidized bed. Fuel Processing Technology, 90(1):113121. [doi:10.1016/j.fuproc.2008.08.004] 
Harrison, D.P., 2008. Sorption-enhanced hydrogen production: a review. Industrial \& Engineering Chemistry Research, 47(17):6486-6501. [doi:10.1021/ie800298z]

He, J., Wu, S.F., 2007. The characteristics of sorption enhanced steam methane reforming for hydrogen production on a complex catalyst. Chemical Reaction Engineering and Technology, 23(5):470-473 (in Chinese).

Inoue, M., Kondo, Y., Inui, T., 1988. An ethylene glycol derivative of boehmite. Inorganic Chemistry, 27(2):215-221. [doi:10.1021/ic00275a001]

Inoue, M., Kominami, H., Inui, T., 1991. Reaction of aluminium alkoxides with various glycols and the layer structure of their products. Journal of the Chemical Society, Dalton Transactions, (12):3331-3336. [doi:10.1039/dt991000 3331]

Inoue, M., Kominami, H., Inui, T., 1994. Synthesis of large pore-size and large pore-volume aluminas by glycothermal treatment of aluminium alkoxide and subsequent calcinations. Journal of Materials Science, 29(9):24592466. [doi:10.1007/BF00363440]

Liu, H.P., Lu, G.Z., Guo, Y., Wang, Y.Q., Guo, Y.L., 2009. Synthesis of mesoporous $\mathrm{Pt} / \mathrm{Al}_{2} \mathrm{O}_{3}$ catalysts with high catalytic performance for hydrogenation of acetophenone. Catalysis Communications, 10(9):1324-1329. [doi:10. 1016/j.catcom.2009.02.014]

Oyekunle, L.O., Ikpekri, O.B., 2004. Modeling of hydrodesulfurization catalysts. I. Influence of catalyst pore structures on the rate of demetallization. Industrial \& Engineering Chemistry Research, 43(21):6647-6653. [doi:10.1021/ie049618y]

Seo, J.G., Youn, M.H., Park, S., Jung, J.C., Kim, P., Chung, J.S., Song, I.K., 2009. Hydrogen production by steam reforming of liquefied natural gas (LNG) over nickel catalysts supported on cationic surfactant-templated mesoporous aluminas. Journal of Power Sources, 186(1): 178-184. [doi:10.1016/j.jpowsour.2008.09.071]

Sun, N.N., Wen, X., Wang, F., Wei, W., Sun, Y.H., 2010. Effect of pore structure on $\mathrm{Ni}$ catalyst for $\mathrm{CO}_{2}$ reforming of $\mathrm{CH}_{4}$. Energy \& Environmental Science, 3(3):366-369. [doi:10. 1039/b925503f]

Wang, S.P., Yan, S.L., Ma, X.B., Gong, J.L., 2011. Recent advances in capture of carbon dioxide using alkali-metalbased oxides. Energy \& Environmental Science, 4(10): 3805-3819. [doi:10.1039/C1EE01116B]

Wu, S.F., Wang, L.L., 2010. Improvement of the stability of a $\mathrm{ZrO}_{2}$-modified Ni-nano-CaO sorption complex catalyst for ReSER hydrogen production. International Journal of Hydrogen Energy, 35(13):6518-6524. [doi:10.1016/j. ijhydene.2010.03.120]

Wu, S.F., Li, Q.H., Kim, J.N., Yi, K.B., 2008. Properties of a nano $\mathrm{CaO} / \mathrm{Al}_{2} \mathrm{O}_{3} \mathrm{CO}_{2}$ sorbent. Industrial \& Engineering Chemistry Research, 47(1):180-184. [doi:10.1021/ ie0704748]

Wu, S.F., Li, L.B., Zhu, Y.Q., Wang, X.Q., 2010. A microsphere catalyst complex with nano $\mathrm{CaCO}_{3}$ precursor for hydrogen production used in ReSER process. Engineering Science, 8(1):22-26.

Xiu, G.H., Li, P., Rodrigues, A.E., 2003. Adsorption-enhanced steam-methane reforming with intraparticle-diffusion limitations. Chemical Engineering Journal, 95(1-3):8393. [doi:10.1016/S1385-8947(03)00116-5]

Xu, Z., Li, Y., Zhang, J.Y., Chang, L., Zhou, R.Q., Duan, Z.T., 2001. Bound-state Ni species: a superior form in Ni-based catalyst for $\mathrm{CH}_{4} / \mathrm{CO}_{2}$ reforming. Applied Catalysis A: General, 210(1-2):45-53. [doi:10.1016/S0926-860X(00) 00798-5] 